Research Article

\title{
Factors Affecting Knowledge Management and Its Effect on Organizational Performance: Mediating the Role of Human Capital
}

\author{
Forouzan Rezaei, ${ }^{1}$ Mohammad Khalilzadeh $\mathbb{D O}^{2}{ }^{2}$ and Paria Soleimani ${ }^{3}$ \\ ${ }^{1}$ Department of Industrial Engineering, Science and Research Branch, Islamic Azad University, Tehran, Iran \\ ${ }^{2}$ Centrum Católica Graduate Business School, Pontificia Universidad Católica del Perú, Lima, Peru \\ ${ }^{3}$ Department of Industrial Engineering, South Tehran Branch, Islamic Azad University, Tehran, Iran \\ Correspondence should be addressed to Mohammad Khalilzadeh; khalilzadeh@pucp.edu.pe
}

Received 26 March 2020; Revised 29 January 2021; Accepted 6 February 2021; Published 19 February 2021

Academic Editor: Christos Troussas

Copyright ( $) 2021$ Forouzan Rezaei et al. This is an open access article distributed under the Creative Commons Attribution License, which permits unrestricted use, distribution, and reproduction in any medium, provided the original work is properly cited.

\begin{abstract}
This study aims to investigate and identify the factors affecting the empowerment and implementation of knowledge management in organizations as well as the impact of knowledge management on organizational performance. This study also examines the mediating role of human capital in the relationship between knowledge management and performance of Kabul Steel Plant, which is the largest steel plant in Afghanistan. The research model was developed through the literature review. The initial data were collected through a questionnaire containing 48 questions. Participants were 108 managers and administrative staff of the company. The collected data were analyzed by using the SPSS and SmartPLS software. The hypotheses regarding the impact of strategy and technology on knowledge management were rejected by using correlation analysis and $t$-test statistic. Finally, the findings showed the positive effects of variables of structure, culture, leadership, and trust on knowledge management in an organization. Also, knowledge management influences the organizational performance, both directly and through the mediating variable of human capital. This research encourages the managers and employees of organizations to use the available organizational resources to implement knowledge management in organizations and improve knowledge management practices and human resources that are the most valuable resources of any organization in order to remain competitive in the markets.
\end{abstract}

\section{Introduction}

Nowadays, knowledge is considered a valuable resource and an asset, and it is difficult and even impossible to deliver quality and economical products and services without using this resource and managing it properly. In this view, knowledge is regarded as a valuable resource alongside other resources such as labor, land, and capital and as an important asset of the organization. Today's professional consulting firms often regard themselves as members of the knowledge industry and provide their staff with opportunities for continuous learning [1].

In general, organizations may either use technologies, or they may have an informal approach to knowledge management. Management should reconsider the pattern of interaction between technologies, people, and the techniques that people apply to utilize these technologies. To maintain the long-term competitive advantage, a company needs to balance its technology systems with its social systems. Technologies can be used to increase people's efficiency and improve the flow of information in the organization [2]. Knowledge management processes (knowledge acquisition, knowledge sharing, and knowledge use) have a positive impact on innovation. In other words, creating or acquiring knowledge, sharing knowledge, or utilizing it will equip staff with skills and pave the way for innovation. Knowledge sharing also has the greatest impact on innovation, because it helps to present new ideas and to benefit from others' experiences. The main limitation in sharing knowledge can be the fear of losing 
control: people do not want to share a great deal of their knowledge because they believe that sharing this knowledge with others reduces their level of power [3].In order to achieve sustainable competition and long-term success, it is necessary to emphasize the proper management of knowledge management activities in the core culture of organizations. Organizations need to create a culture in which employees can be motivated to share knowledge as a result of realizing their personal and organizational objectives. Organizations should particularly emphasize the sharing of knowledge gained through internal and external resources among their staff [4].

The main challenge for organizations is to understand knowledge management and how to implement it in the form of a knowledge management system, and many companies and organizations around the world have already invested in knowledge management. Despite the success of many, some organizations have also failed. A number of circumstances, situations, and challenges seem to lead to the ultimate success or failure of knowledge management activity in an organization. Therefore, before an organization's scarce resources are invested in such a risky area, management must seek tools to reduce the uncertainty of the knowledge management project.

The extent to which an organization is capable of creating organizational values depends on its ability to create, transfer, and use knowledge, which also increases organizational competition. Knowledge management activities such as acquisition, creation, sharing, and use or application of knowledge are investigated, which also increases the competitiveness of the organization. On the other hand, researchers seek to identify incentives such as organizational structure, leadership, culture, and other factors that facilitate knowledge management processes or activities [5]. The impact of knowledge management in knowledge-based institutions such as universities for better return on investment in terms of intellectual capital (IC) and innovation is inevitable. Hence, this field has attracted the attention of scholars and researchers in recent years. Reviewing the existing literature on knowledge management helps with identifying some of the essential gaps that need to be addressed [6].

The main challenge of organizations is to first understand knowledge management and how to implement it in the form of an integrated knowledge management system. Second, organizational knowledge management is not limited to identifying the influencing factors or processes affecting the implementation of knowledge management, and another question that needs to be considered is the measurable results of knowledge management, in which the effect of knowledge management on organizational performance should be examined because it is still unclear [7]. For example, many organizations, especially in developing countries, generally have problems with individual culture, organizational structure, lack of leadership participation in knowledge management activities, low awareness of the benefits of knowledge management, and lack of incentive system. As a result, an integrated and coherent knowledge management strategy is essential in any organization that leads to effective knowledge management to increase innovation and performance [8].
A number of researchers such as Hsu [9] and LópezNicolás [10] claim that knowledge management does not directly affect organizational performance because there are other mediator variables that transmit knowledge management effects to organizational performance. The role of mediator variables between the knowledge management and organizational performance processes is still unclear and there exist some gaps in the literature that need to be further investigated [11]. Knowledge management creates a creative environment that enables organizations to achieve advanced performance [12].

Therefore, this study intends to identify the gap in previous research with empirically examining the empowerment of knowledge management and the processes affecting knowledge management. Also, this paper investigates the impact of mediating variables on knowledge management and organizational performance. In particular, the current study seeks to address the following questions:

Question 1: are factors such as leadership, culture, and structure affecting empowerment and implementation of knowledge management in the organization?

Question 2: does knowledge management directly affect organizational performance?

Question 3: is human capital as an important resource in the organization mediating the relationship between knowledge management and organizational performance?

\section{Theoretical Background and Hypotheses}

This section deals first with the theoretical foundations, literature review, and research method. Knowledge is the understanding, awareness, or cognition which is created through the study, observation, experience, and research of the outside world in the individual and is an intangible resource which is combined with other organizational resources (such as financial and physical) to build capabilities [13]. Knowledge management is an integrated process that collects, stores, and shares knowledge in an organization. Although knowledge sharing is not simple, it is encouraged among organizational staff [14]. HR practices cause employees to seek knowledge of innovative products and services and reach a higher level of conversation and learning and help them discover knowledge from external sources, which is crucial for companies. The methods of human resource management create a credible and robust organizational climate that can influence the staff's flexibility, that is to what extent, if any, they feel comfortable to share ideas and insights. Obviously, utilizing relevant knowledge through information and communications, technology is essential for knowledge exploitation, and in turn, for knowledge discovery [15]. Knowledge management can be defined as an organized approach designed to manage the production, sharing, and harvesting; it is also how to use knowledge leverage as an organizational achievement to enhance the ability, speed, and effectiveness of an organization to offer and deliver goods and services to customers [16]. For the past two decades, organizations have been 
actively seeking competitive advantages such as product leadership, cost leadership, and being different from competitors. Knowledge management has received considerable attention in management circles because of its capability to provide organizations with strategic outcomes related to profitability, competitiveness, and capacity development [17].

2.1. Knowledge Management Processes. In organizations, knowledge management activities do not occur individually. There are specific organizational factors that contribute to the knowledge management initiative and facilitate knowledge-related activities [18]. Several studies have identified and examined the organizational factors affecting knowledge management which are broadly presented in this section. The most common knowledge management factors examined so far are leadership, senior management support, organizational human resource practices, culture, structure, climate, and technology [19].

Establishment and development of external and internal knowledge management committees within the organization promote communication and networking and result in reducing boundaries and fostering the sharing and transferring of knowledge. Knowledge management methods, systems, and practices should also be evaluated to determine which methods, systems, and practices are effective and which are not [20]. The sources of knowledge stem from organizational strategy, culture, and, structure, because the created knowledge is sensitive, and are used in light of a series of cultural norms and values involved in structural interactions and echoed in strategic priorities [21]. A study showed how organizations can work to ensure knowledge sharing in their workplaces in Malaysian companies and create a helpful environment for knowledge sharing and considered organizational culture and structure a prerequisite for knowledge transfer. They also explain how organizational structure and culture contribute to the process of knowledge sharing, with the moderating impact of technological infrastructure [22]. Another study investigated the influence of team culture, knowledge sharing, and team emotional intelligence on team performance and confirmed the strong association between team culture and team performance [23].

The mediating role of social capital in the relationship between organizational culture and knowledge management as well as the direct impact of culture on knowledge management has been investigated. The results showed that organizational culture has a positive and significant effect on knowledge management and social capital. Another study examined the impact of culture, technology and structure, etc. using SEM with PLS software. The negative impact of technology on knowledge management and the positive effects of culture and the structure on knowledge management were shown [24].

In addition, if we want to approach the knowledge management effectively, we should use appropriate strategies with regard to the knowledge and organization. Knowledge management strategy is an effective factor on innovation and organizational performance [25]. Implicit knowledge transfer is important for organizations to ensure that individual expertise is transferred or spread across the whole team or department rather than centralized in one employee. This is especially important to IT professionals, because in addition to technical knowledge, they often combine prior knowledge and experience to solve day-today problems and to implement and develop new systems. Finally, hard-working, responsible, and introverted employees tend to share their tacit knowledge when they feel they are in a supportive and team-oriented environment and have good social interactions in the workplace [26].

Initiating knowledge management activities has been challenging in many organizations because focusing on the wrong activities and not providing enough leadership leads to many failures. Leadership style which is particularly related to knowledge infrastructure including organizational culture, organizational structure, and information technology significantly has a crucial role in the success of knowledge management activities. Managers should use transformational leadership style when promoting knowledge management initiatives in organizations [27]. Effective leadership is a prerequisite for building trust within organizations. Also, knowledge management processes can contribute to organizational performance [28, 29]. Effective leadership (individual leadership, organizational leadership, and people leadership) leads to mutual trust among people, promotes successful implementation of knowledge management processes, and in turn, enhances organizational performance. Therefore, training in leadership and development must be a top strategic priority for any organization [19]. Factors which contribute to enhancing knowledge sharing by means of suggestions and the empirical validation of a theoretical model include three major aspects: (1) anticipated advantages related to knowledge sharing. (2) Trust in the workplace to appreciate knowledge sharing activities and intention. (3) Staff's understanding of knowledge sharing. Expected advantages include 3 incentives, namely, expected reward, expected relationship, and expected participation. Trust also plays an important part in sharing knowledge in companies [30]. The results of a study show that trust improves the knowledge sharing behavior of nonacademic staff of higher learning institutions [31].

Therefore, the factors affecting knowledge management as the key to success and influencing its effectiveness are comprehensively identified and divided into six categories. These factors are first defined, and then the relevant hypotheses are presented: (1) organizational structure allocates work roles and controls and integrates work activities [32]. In highly formalized organizations, there are explicit rules and procedures that may impede the self-belief and the flexibility required for internal creativity. In less formalized organizations, occupational behaviors are almost less structured, and the staff are more free to deal with demands related to their duties [33]. (2) Taking advantage of appropriate strategies and using knowledge management are essential for an organization to survive in the world of competition [34]. The concept of strategy is based on three elements: competitive advantage, distinct capabilities, and 
strategic coordination. (3) Technology can be defined as all the knowledge, goods, processes, tools, methods, and systems used to produce goods and offer services. The IT infrastructure supports the transfer of tacit knowledge to explicit knowledge [35]. It also allows explicit knowledge to be stored and recorded in official documents to facilitate knowledge retrieval [36]. (4) Culture is a collection of traits that distinguishes one group, organization, or nation from others [37]. From the critics' point of view, organizational culture can be viewed as a continuous process of identity building/rebuilding in and around the organization [38]. (5) Leadership involves communicating between the leader and the follower to achieve the desired results [39]. Trust is an essential component of successful and efficient teamwork [40]. Leadership directly influences knowledge sharing climate and behavior, interpersonal trust, and organizational learning of an organization. Interpersonal trust directly influences knowledge sharing behavior and indirectly influences organizational learning through knowledge sharing behavior [41]. (6) Trust is the basis for creating commitment among members of an organization for knowledge management and depends on two factors: (1) measures taken to strengthen trust within organizations; (2) employees' perception of how knowledge sharing leads to personal advantages [30]. Trust positively and significantly influences knowledge sharing and affective and normative organizational commitment. Knowledge sharing partially mediates the relation between trust and affective organizational commitment [42]. For these reasons, we provide the following hypotheses:

$H 1$. Organizational structure has a positive effect on knowledge management [22, 43]

H2. Organizational strategy has a positive effect on knowledge management [43]

H3. Organizational technology has a positive effect on knowledge management [22]

H4. Organizational culture has a positive effect on knowledge management $[22,24]$

H5. Organizational leadership has a positive effect on knowledge management [29]

H6. Trust in the workplace has a positive effect on knowledge management $[19,29]$

\subsection{Knowledge Management and Human Capital and Or-} ganizational Performance. The results of a study examining users' perceived benefits and users' satisfaction in organizational knowledge management systems and providing a model for it show that knowledge is valuable only when it has been created within the right framework, production time, and in accordance with a query. At the system level, the performance of organizational knowledge must be measured. Acquisition, maintenance, repair, search, and retrieval are factors affecting knowledge management. These factors are based on storing knowledge in the system to integrate it with old knowledge and maintain its integrity, as well as provide search and retrieval capabilities in the system.
It was claimed that in order to pave the way for achieving high levels of quality, members of the system need to be connected and converse to each other [44]. A study which has examined the relationship between knowledge management process, knowledge management performance, and job performance considers the knowledge management process as consisting of seven constituents: knowledge recognition, knowledge creation, knowledge gathering, knowledge organization, knowledge storage, knowledge dissemination, and knowledge application [45].

In the customer-centric age, customer relationship management and customer knowledge management are among the most important issues for organizations. They both emphasize how to integrate and distribute resources to improve organizational performance and increase competitive advantage. Proper understanding of customer's needs is a result of customer knowledge management, which ultimately plays a key role in building customer relationships. When knowledge is freely disseminated and distributed in an organization, its potential values emerge. If knowledge is properly used in an organization and new knowledge is vastly created, it not only increases productivity but also promotes creativity. In today's information society, human capital has assumed more importance than economic capital $[46,47]$.

Human capital is the ability of an organization to create value through the use of experience, learning, skills, training, and creativity of its employees. How team members use their limited human and psychological capital to make social knowledge effective is an important factor in improving the performance and knowledge sharing of an organization's employees [48]. Human capital is defined as the knowledge, skills, and abilities that indigenous people acquire through investment in education and other types of experiences [49]. The theory of human capital states that people with higher levels of knowledge, training, and other skills perform better than others. From the perspective of organizational psychology, human capital is described as a distinctive and valuable resource that others cannot easily copy or replace them. Human capital is measured with elements such as managerial experience, work experience, level of education, and training [50]. Knowledge management is needed as an important resource for the implementation of human capital to improve innovation [51].

Investigating the relationship between knowledge management and intellectual capital of the organization is a research topic whose results show a significantly positive relationship between these two variables, both of which have a significant impact on improving the organizational performance [52]. Another study that indicates the positive impact of knowledge management on human capital and organizational performance through the mediating effect of learning culture defines learning culture as a combination of organizational culture and organizational learning and training [53]. Knowledge management processes influence organizational performance directly and indirectly through innovation and intellectual capital [5].

The relationship between knowledge management and organizational performance is an interesting field for 
researchers and practitioners, and further studies are needed to clarify this relationship. Knowledge management practices including knowledge creation practices, continuous learning practices, knowledge systems, and employee competency management affect the financial and nonfinancial performance of the organization [7].

The key issue for researchers studying knowledge management is to examine the ways in which knowledge management affects organizational performance. The most effective aspect of knowledge management is the use of knowledge to influence performance. In addition, studies have shown that knowledge transfer is a common knowledge management process conducted by organizational staff [54]. Another study that demonstrates the positive impact of knowledge management on organizational performance considers knowledge management as being deeply rooted in seven factors, namely, direct leadership and support, organizational culture, organizational strategies, processes and activities, information technology, training, and incentives; it also regards performance variable as being based on four factors, namely, learning and growth, internal processes, customer, and financial perspectives [55]. The research hypotheses are thus as follows:

$H 7$. Knowledge management has a positive effect on the development of human capital [53]

H8. Human capital development has a positive effect on organizational performance [53]

The main hypothesis:

H9. Knowledge management has a positive effect on organizational performance

H9.a. Knowledge management directly has a positive effect on organizational performance $[19,29,53,55]$ H9.b. Knowledge management indirectly and through the mediation of human capital has a positive effect on the performance of the organization [53]

2.3. Statement of the Problem. Due to the complex and abundant resources in the field of organizational knowledge management, many strategies adopted so far have been inefficient and incompatible. Therefore, finding the most influencing factors of knowledge management and performance has been one of the most important concerns of managers. This research attempts to provide a more comprehensive and practical organizational knowledge management model for managers. Many studies have been conducted on knowledge management, especially the impact of knowledge management on organizational performance through mediating variables. For example, Iqbal et al. [5] only examined the impact of three actors including leadership, culture, and incentives on the knowledge management process and dealt with the impact of knowledge management on the performance of organization through the mediating role of intellectual capital. Another similar study conducted by Ogunmokun et al. [56] investigated the effect of trust on knowledge sharing behavior and service innovation, which shows the positive effect of trust on knowledge sharing behaviors in the organization. The difference between the present study and previous research is that previous research has addressed the positive effect of trust on only one aspect of knowledge management, namely, knowledge sharing, while this study examines the effect of trust on knowledge management in general. Many studies have examined only one activator and its effect on the knowledge management process. The effect of knowledge-oriented leadership on knowledge management process and the effect of trust on knowledge management processes are the only factors that have been investigated in the past studies [57]. Knowledge-oriented leadership is another factor whose impact on knowledge management and organizational performance has been individually studied [57].

Previous studies have examined only one or a very limited number of knowledge management activists, while more activists can be considered in a more comprehensive research model. It helps the managers of organizations to have a better view for knowledge creation and performance improvement in organizations in order to survive in today's competitive environment. On one hand, this study attempts to investigate the maximum possible factors affecting knowledge management, and on the other hand, it tries not to make the model too complex and incomprehensible. Another important distinction of this study is the scrutiny of the mediating variable of human capital in the relationship between knowledge management and organizational performance; only few studies have addressed this issue. For instance, similar studies such as [57] examined the mediating role of knowledge worker productivity in the relationship between knowledge management and organizational performance. Also, another study addressed the impact of knowledge management processes on organizational performance [58]. Human capital as an independent variable also affects the performance of the organization [59]. Finally, investigating human capital mediating role in the relationship between knowledge management and organizational performance is a new topic that is addressed in this study.

The general objective of this study is to investigate both the direct effect of knowledge management on organizational performance and its effect through the mediating variable of human capital. The specific objectives of the research are to examine the effects of the factors: structure, strategy, culture, technology, leadership, and trust on the implementation of knowledge management in the organization. The dependent variable, namely, knowledge management (including knowledge creation, identification, sharing, and application) can be attributed to the 6 independent variables of culture, structure, strategy, leadership, trust, and technology in the organization. These 6 variables influence the dependent variable (knowledge management) in different ways and to different extents. The sources of knowledge in the organization are the products of culture, structure, strategy, leadership, trust, and technology, as shown in Figure 1.

\section{Research Methodology}

In this study, a questionnaire was used to collect the required research data. The questionnaire used in this study consists of 48 questions examining the impact of organizational structure, strategy, technology, culture, 


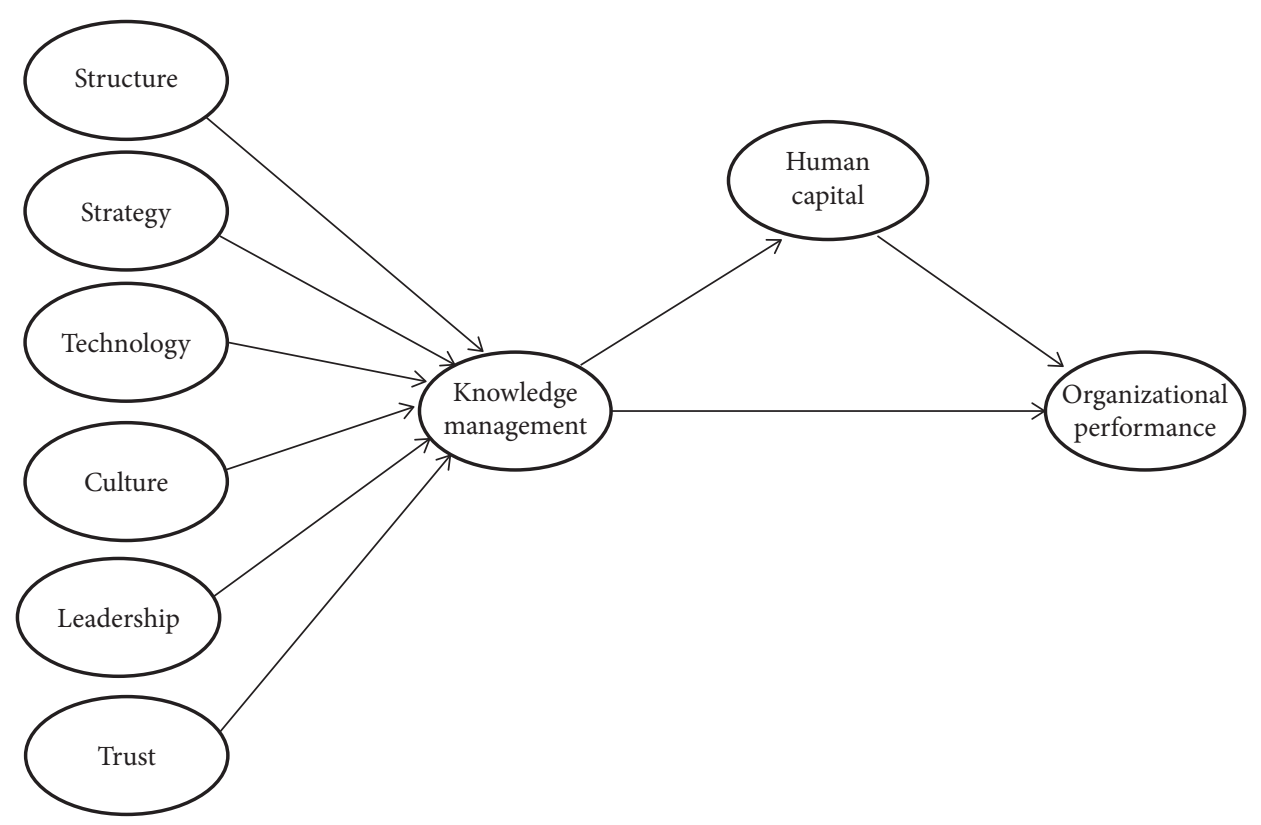

Figure 1: The conceptual model.

leadership, and trust on knowledge management, as well as the impact of knowledge management on human capital, and ultimately on the performance of Kabul Steel Plant. To this end and to design questionnaire questions for culture, structure, strategy, and technology constructs, the research background and articles such as [22, 55] were used. Standard questionnaires from papers by $[60,61]$ and [53] have also been used for leadership, trust, knowledge management, human capital, and performance constructs. The questionnaire included demographic questions including the parameters age, gender, work experience, and education level. In order to measure the indices in the questionnaire, the 5-point Likert scale was used, which is one of the most common measurement scales. For validity purposes, mostly standard questionnaires were used in this study. After the questionnaires were prepared, they were distributed among a number of professors and experts, as well as a number of managers in the target community, and necessary modifications were made based on their comments. Content validity ratio (CVR) and content validity index (CVI) were used to assess their content validity. As a result, by distributing the questionnaire to 10 experts, the CVR values (according to the standard table) exceeded 0.62; thus, the content validity of the questionnaire items was confirmed. Also, by calculating the CVI value of all items and obtaining an average value of 0.81 which is greater than the minimum value of 0.79 , the content validity of the scale was confirmed. Cronbach's alpha was applied to check the reliability of the questionnaire. An alpha above 0.7 is usually acceptable. To assess the reliability of the questionnaire, Cronbach's alpha was calculated using SPSS software. Cronbach's alpha for each of the scales was above 0.70 , as shown in Table 1 .

The statistical population of this research consists of all the administrative employees of Kabul Steel Plant. They were 150 people at the time of this study. According to Cochran's formula, the sample size was 108 , which was calculated by the following equation:

$$
\text { Sample size }=\frac{N \cdot Z_{\alpha / 2}^{2} \cdot p q}{e^{2} \cdot(N-1)+Z_{\alpha / 2}^{2} \cdot p q},
$$

where $N$ is the population size, $p$ and $q$ are usually set to 0.5 , $e$ is set to less than $10 \%(e=0.05)$, and the amount of $z$ with the assumption of $\alpha=0.05$ is found from the normal distribution table $(z=1.96)$.

Questionnaires were randomly distributed among the employees of the administrative department and finally 108 questionnaires were extracted according to the sample size. The demographic data are presented in Table 2.

In this study, the data obtained from the questionnaires were analyzed using descriptive, inferential, and confirmatory factors analysis by SPSS and SmartPLS software. After determining the normality of the data and doing the Bartlett and KMO tests, each research hypothesis was analyzed separately using the partial least squares technique. The general research model was also examined using this technique. In general, the evaluation of structural equation models covers three sections of measurement models, the structural model, and the general research model (measurement and structural) that must be examined in order.

\section{Data Analysis and Results}

Demographic data showed $34.3 \%$ of the respondents were females and $65.7 \%$ were males. Also, the highest frequency of age was between 32 and 37 years with $35.2 \%$. Finally, in terms of education level, the highest number belonged to bachelor's degree (42.6\%), and the lowest number belonged to doctoral education (5.6\%). The results of the normality test are shown in Table 3. 
TABLE 1: Reliability analysis of research questionnaire.

\begin{tabular}{lccr}
\hline Scales & Cronbach's alpha & $N$ & Sources of measurement instruments \\
\hline Organizational structure & 0.846 & $\mathbf{5}$ & {$[22]$} \\
Organizational strategy & 0.781 & $\mathbf{5}$ & {$[43]$} \\
Organizational technology & 0.876 & $\mathbf{5}$ & {$[22]$} \\
Organizational culture & 0.874 & $\mathbf{5}$ & {$[22]$} \\
Organizational leadership & 0.822 & $\mathbf{5}$ & {$[60]$} \\
Trust in workplace & 0.880 & $\mathbf{6}$ & {$[61]$} \\
Knowledge management & 0.875 & $\mathbf{5}$ & {$[53]$} \\
Human capital & 0.901 & $\mathbf{5}$ & {$[53]$} \\
Organizational performance & 0.875 & $\mathbf{5}$ & {$[53]$} \\
Total & 0.947 & $\mathbf{4 8}$ & \\
\hline
\end{tabular}

TABLE 2: The demographic data.

\begin{tabular}{lccc}
\hline Characteristics & Values & Frequency & Percentage \\
\hline \multirow{2}{*}{ Gender } & Male & 71 & 65.7 \\
& Female & 37 & 34.3 \\
\hline \multirow{3}{*}{ Age } & 20 to 30 & 29 & 26.8 \\
& 31 to 41 & 24 & 50.9 \\
\hline \multirow{3}{*}{ Experience } & More than 42 & 12 & 22.3 \\
& Under 5 & 51 & 11.1 \\
& 5 to 10 & 45 & 47.2 \\
\hline
\end{tabular}

TABLe 3: The normality test (kurtosis and skewness).

\begin{tabular}{|c|c|c|c|c|c|}
\hline Variables & Number & Skewness (statistic) & Skewness (SD) & Kurtosis (statistic) & Kurtosis (SD) \\
\hline Organizational structure & 108 & 0.573 & 0.233 & 0.550 & 0.461 \\
\hline Organizational strategy & 108 & -1.343 & 0.233 & 2 & 0.461 \\
\hline Organizational technology & 108 & -0.485 & 0.233 & 0.404 & 0.461 \\
\hline Organizational culture & 108 & -0.921 & 0.233 & 1.221 & 0.461 \\
\hline Organizational leadership & 108 & -0.823 & 0.233 & 0.847 & 0.461 \\
\hline Trust in workplace & 108 & -0.975 & 0.233 & 1.618 & 0.461 \\
\hline Knowledge management & 108 & -0.257 & 0.233 & -0.503 & 0.461 \\
\hline Human capital & 108 & -1.113 & 0.233 & 1.675 & 0.461 \\
\hline Organizational performance & 108 & -0.695 & 0.233 & 0.706 & 0.461 \\
\hline
\end{tabular}

Based on the test results shown in Table 3, the skewness statistics of all the variables ranged from -2 to 2 , the kurtosis statistics from -3 to 3 , and their standard deviation ranged from -2 to 2 . Therefore, it can be concluded that the research data were normally distributed.

According to Table 4, since the significance level of the test is less than 0.05, the assumption of independence of all variables is rejected, and thus, at least one pair of parameters is not independent. Also, the KMO values of all variables were greater than 0.7 and were appropriate. Therefore, it is possible to perform factor analysis techniques for all 9 research indicators.

4.1. Confirmatory Factor Analysis to Respond to Research Hypotheses. After designing the general research model, the measurement model (relationship of each latent variable with observed variables), the structural model (relationship of latent variables with each other), and, finally, fitting the general model of the research were investigated in a stepwise manner. The $t$-statistics has been computed using the bootstrap method for the significance of the relationships. Finally, a test of research hypotheses based on the relationships of each variable was also presented separately.

Figure 2 shows values of factor loading in the output, and Figure 3 shows the significance values ( $t$-statistics) of the relationships between the variables.

4.2. Analysis of Fit Indices of Measurement Model. Significance of factor loading and $t$ values: the factor loading values and $t$-statistics of the measurement model are shown in Table 5. The factor loading value in all cases should be greater than 0.4 , indicating a good correlation between the observed variables and their respective latent variables. Also, the $t$ statistics between the observed variables and their respective latent variables in all cases must be greater than 1.96.

The analysis of reliability of research variables, convergent validity, and quality of CVR and CVC measurement model: Cronbach's alpha for all variables should be greater 
TABLe 4: Bartlett test and KMO test.

\begin{tabular}{lcccc}
\hline Variables & KMO test & Bartlett test $>$ chi-square & Bartlett test $>$ d.f & Bartlett test $>$ Sig \\
\hline Organizational structure & 0.862 & 279.562 & 10 & 0.000 \\
Organizational strategy & 0.772 & 151.572 & 10 & 0.000 \\
Organizational technology & 0.809 & 327.632 & 10 & 0.000 \\
Organizational culture & 0.866 & 261.275 & 10 & 0.000 \\
Organizational leadership & 0.777 & 214.607 & 15 & 0.000 \\
Trust in workplace & 0.805 & 358.452 & 10 & 0.000 \\
Knowledge management & 0.744 & 360.621 & 10 & 0.000 \\
Human capital & 0.798 & 430.837 & 21 & 0.000 \\
Organizational performance & 0.840 & 360.106 & 1128 & 0.000 \\
All questions & 0.812 & 7770.156 & 0.000 \\
\hline
\end{tabular}

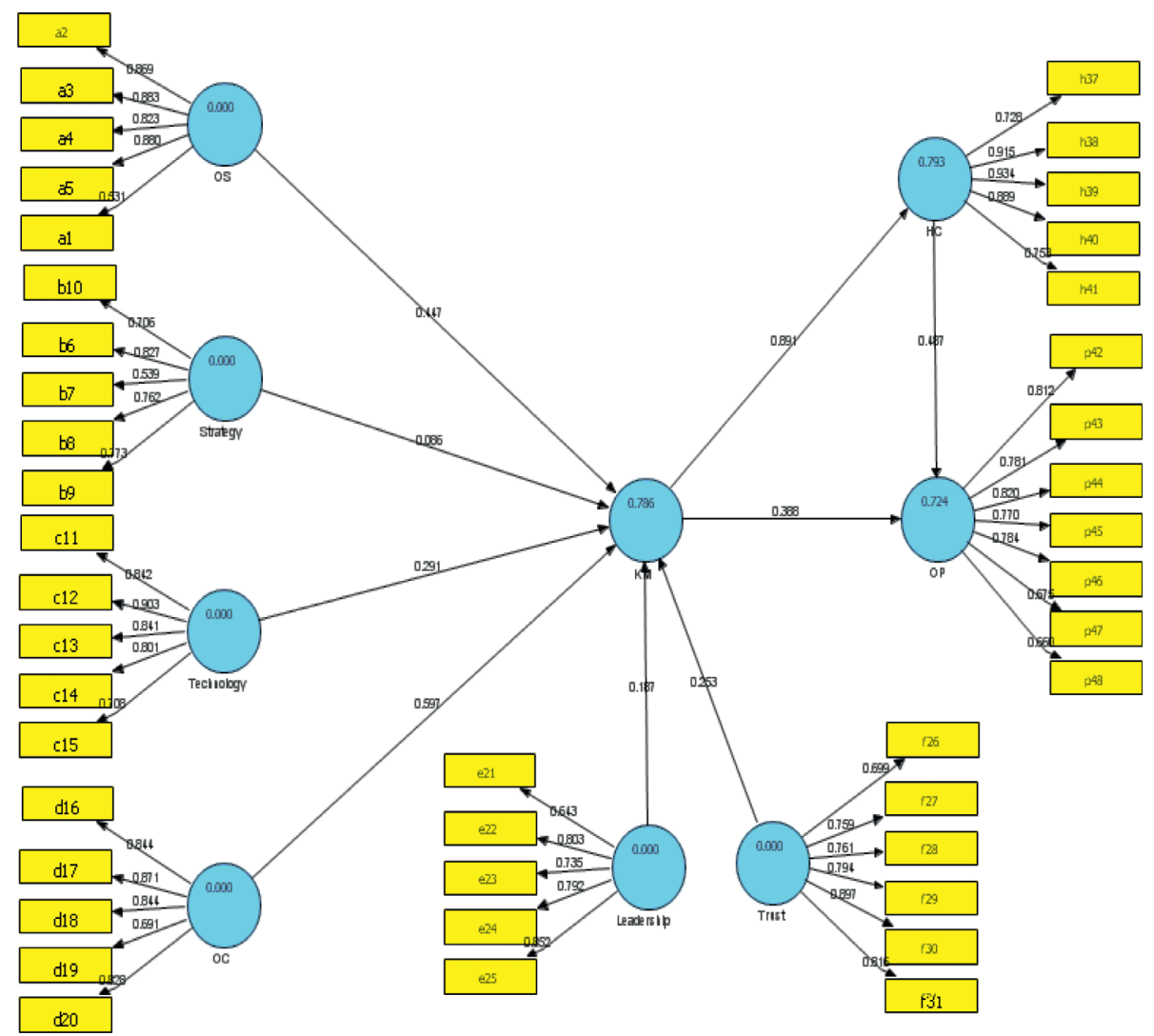

Figure 2: Factor loading values for the general research model.

than 0.7, and the average variance extracted (AVE) should always be greater than 0.4 , and the composite reliability (CR) value should be greater than AVE. Therefore, the reliability of the research variables is confirmed. Quality indices should always have positive values. Therefore, the model has acceptable quality and reliability. Table 6 presents the reliability and validity of the variables and other relevant indices.

Significance of factor loading values between questions and latent variables, Cronbach's alpha, composite reliability, average variance extracted (AVE), quality of CVR, and CVC measurement model all indicate the suitability of the measurement model; that is, the questionnaire used in this study measures what the researcher intended.
4.3. Analysis of Structural Model Fit Indices. Path coefficients and its significance values ( $t$ value): relationships between latent variables of the model are significant if the calculated $t$ values are greater than 1.96 (shown in Table 7).

$Q^{2}$ (Stone-Geisser criterion) and $R^{2}$ : this criterion specifies the predictive power of the model. The value of $Q^{2}$ must be calculated for all endogenous structures of the model. The three values of $0.02,0.15$, and 0.35 determine the model's predictive power for endogenous structures, respectively, indicating low, medium, and high predictive power. $R^{2}$ is a criterion showing the influence of an exogenous variable on an endogenous variable, and the three values of $0.19,0.33$, and 0.67 are considered as the criterion values for weak, moderate, 




FIGURE 3: $t$-statistics of general research model.

TABLE 5: Factor loading and t-statistics values of external model.

\begin{tabular}{|c|c|c|c|}
\hline & Questions & Factor loading values & $t$-statistics \\
\hline \multirow{5}{*}{ Organizational structure } & a1 & 0.531 & 5.788 \\
\hline & $\mathrm{a} 2$ & 0.869 & 20.676 \\
\hline & a3 & 0.883 & 14.335 \\
\hline & a4 & 0.823 & 18.790 \\
\hline & a5 & 0.880 & 27.585 \\
\hline \multirow{5}{*}{ Strategy } & b6 & 0.827 & 24.635 \\
\hline & b7 & 0.539 & 4.193 \\
\hline & b8 & 0.762 & 11.104 \\
\hline & b9 & 0.773 & 15.253 \\
\hline & b10 & 0.706 & 7.665 \\
\hline \multirow{5}{*}{ Technology } & $\mathrm{c} 11$ & 0.842 & 19.376 \\
\hline & $\mathrm{c} 12$ & 0.903 & 36.215 \\
\hline & $\mathrm{c} 13$ & 0.841 & 23.773 \\
\hline & $\mathrm{c} 14$ & 0.801 & 17.638 \\
\hline & $\mathrm{c} 15$ & 0.708 & 15.877 \\
\hline \multirow{5}{*}{ Culture } & $\mathrm{d} 16$ & 0.844 & 21.903 \\
\hline & $\mathrm{d} 17$ & 0.871 & 39.605 \\
\hline & $\mathrm{d} 18$ & 0.844 & 15.833 \\
\hline & $\mathrm{d} 19$ & 0.691 & 8.363 \\
\hline & $\mathrm{d} 20$ & 0.828 & 23.606 \\
\hline \multirow{5}{*}{ Leadership } & e21 & 0.643 & 12.021 \\
\hline & $\mathrm{e} 22$ & 0.803 & 17.558 \\
\hline & e23 & 0.735 & 11.006 \\
\hline & $\mathrm{e} 24$ & 0.792 & 9.961 \\
\hline & e25 & 0.852 & 19.550 \\
\hline \multirow{6}{*}{ Trust } & $\mathrm{f} 26$ & 0.699 & 9.400 \\
\hline & $\mathrm{f} 27$ & 0.759 & 11.505 \\
\hline & $\mathrm{f} 28$ & 0.761 & 11.502 \\
\hline & f29 & 0.794 & 14.921 \\
\hline & $\mathrm{f} 30$ & 0.897 & 44.434 \\
\hline & f31 & 0.816 & 14.271 \\
\hline
\end{tabular}


TABLE 5: Continued.

\begin{tabular}{lccc}
\hline & Questions & Factor loading values & $t$-statistics \\
\hline & $\mathrm{m} 32$ & 0.742 & 11.038 \\
& $\mathrm{~m} 33$ & 0.846 & 24.807 \\
Knowledge management & $\mathrm{m} 34$ & 0.775 & 0.709 \\
& $\mathrm{~m} 35$ & 0.857 & 29.141 \\
& $\mathrm{~m} 36$ & 0.872 & 22.661 \\
\hline & $\mathrm{h} 37$ & 0.728 & 10.517 \\
Human capital & $\mathrm{h} 38$ & 0.915 & 28.427 \\
& $\mathrm{~h} 39$ & 0.934 & 63.577 \\
& $\mathrm{~h} 40$ & 0.889 & 34.124 \\
& $\mathrm{~h} 41$ & 0.753 & 12.288 \\
\hline & $\mathrm{p} 42$ & 0.812 & 14.579 \\
& $\mathrm{p} 43$ & 0.781 & 10.837 \\
& $\mathrm{p} 44$ & 0.820 & 16.033 \\
& $\mathrm{p} 45$ & 0.770 & 15.472 \\
& $\mathrm{p} 46$ & 0.784 & 14.216 \\
& $\mathrm{p} 47$ & 0.675 & 10.245 \\
& $\mathrm{p} 48$ & 0.660 & 10.077 \\
\hline
\end{tabular}

TABLE 6: Convergent validity and reliability of the research variables.

\begin{tabular}{lcccrrr}
\hline Variables & Number of questions & Cronbach's alpha & AVE & CR & CVR & CVC \\
\hline Organizational structure & 5 & 0.857 & 0.653 & 0.901 & 0.488 & 0.488 \\
Organizational strategy & 5 & 0.784 & 0.530 & 0.847 & 0.294 & 0.294 \\
Organizational technology & 5 & 0.877 & 0.674 & 0.911 & 0.508 & 0.508 \\
Organizational culture & 5 & 0.874 & 0.699 & 0.909 & 0.495 & 0.495 \\
Organizational leadership & 5 & 0.822 & 0.590 & 0.877 & 0.384 & 0.384 \\
Trust in workplace & 6 & 0.880 & 0.624 & 0.908 & 0.476 & 0.476 \\
Knowledge management & 5 & 0.877 & 0.671 & 0.910 & 0.466 & 0.503 \\
Human capital & 5 & 0.899 & 0.719 & 0.926 & 0.529 & 0.577 \\
Organizational performance & 7 & 0.876 & 0.577 & 0.904 & 0.400 & 0.431 \\
\hline
\end{tabular}

and strong values of $R^{2}$. The results for these two indices are shown in Table 8 .

The significance value of $t$ among the latent variables indicates that the relationship between strategy and organizational technology with knowledge management has not been significant; however, it was significant for other variables. Also, the $Q^{2}$ and $R^{2}$ criteria indicate strong predictive power of the model and confirm the appropriate fit of the research structural model.

4.4. Goodness of the Fit for the Overall Model (Overall Quality Test). According to Table 9, the GOF value is 0.68 , which is greater than 0.36 , signifying the goodness of the fit for the overall model.

4.5. Testing Research Hypotheses. The results of evaluation of measurement model, structural model, and general model show the suitability of the research model, and the research hypotheses are investigated accordingly. Since the relationship between organizational strategy and organizational technology with knowledge management was not significant, these two variables were eliminated to modify the model. So, we remove these two variables from the model and implement a new model whose results and software output are shown in Figures 4 and 5.

The direct relationship between knowledge management and organizational performance was calculated as 0.387 . Test statistic was obtained to be 2.486. However, knowledge management also has an indirect impact on the organizational performance through the mediating effect of human capital. The indirect impact of knowledge management on organizational performance is $0.891 \times 0.487=0.433$, and finally, its total impact is 0.820 , which indicates that the observed effect is significant. Thus, knowledge management has a positive impact on organizational performance with 95\% confidence.

The relationship between the variables and the test statistics of the research hypotheses is shown in Table 10. Given the $t$-statistics, which in all assumptions was greater than the critical value of $t$ at $5 \%$ error level that is 1.96 , the observed effect is significant. Thus, it shows the positive effects of the research variables with $95 \%$ confidence.

\section{Discussion}

The aim of this study was to investigate the effect of empowering factors on knowledge management, the direct effect of knowledge management on organizational 
TABLE 7: Factor loading values and significance of $t$ values between latent variables.

\begin{tabular}{lcccc}
\hline Exogenous variable & Endogenous variable & Path coefficient & $t>1.96$ & Result \\
\hline Organizational structure & Knowledge management & 0.447 & 2.582 & Confirmed \\
Organizational strategy & Knowledge management & 0.086 & 0.960 & Rejected \\
Organizational technology & Knowledge management & 0.291 & 1.780 & Rejected \\
Organizational culture & Knowledge management & 0.597 & Confirmed \\
Leadership & Knowledge management & 0.187 & 2.057 & Confirmed \\
Trust & Knowledge management & 0.253 & 2.254 & Confirmed \\
Knowledge management & Human capital & 0.891 & 46.141 & Confirmed \\
Human capital & Performance & 0.487 & Confirmed \\
Knowledge management & Performance & 0.388 & 2.814 & Confirmed \\
\hline
\end{tabular}

TABLE 8: $Q^{2}$ and $R^{2}$ coefficients for research variables.

\begin{tabular}{lcr}
\hline Endogenous structure & $Q^{2}$ & $R^{2}$ \\
\hline Human capital & 0.52 & 0.79 \\
Knowledge management & 0.49 & 0.77 \\
Organizational performance & 0.39 & 0.72 \\
\hline
\end{tabular}

TABle 9: GOF value.

\begin{tabular}{lcc}
\hline$(\overline{R \text { Square }})^{2}$ & $(\overline{\text { Communality }})$ & GOF $=\sqrt{(\overline{\text { Communality }}) \times(\overline{R \text { Square }})^{2}}$ \\
\hline 0.76 & 0.62 & 0.68 \\
\hline
\end{tabular}

Note. Three values of $0.01,0.25$, and 0.36 indicate weak, moderate, and strong fits, respectively.

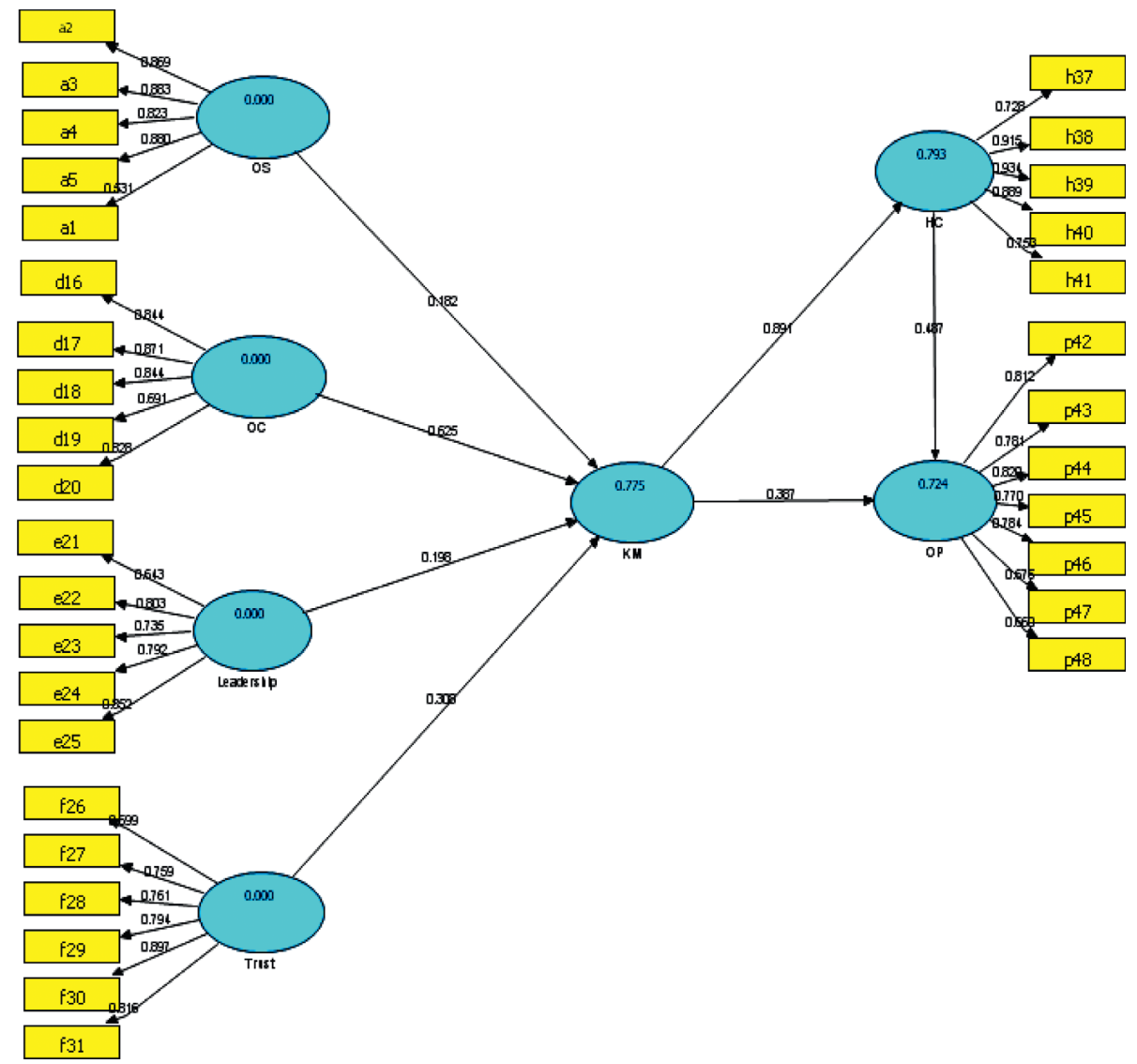

FIGURE 4: Loading factors of research model after removing insignificant paths. 


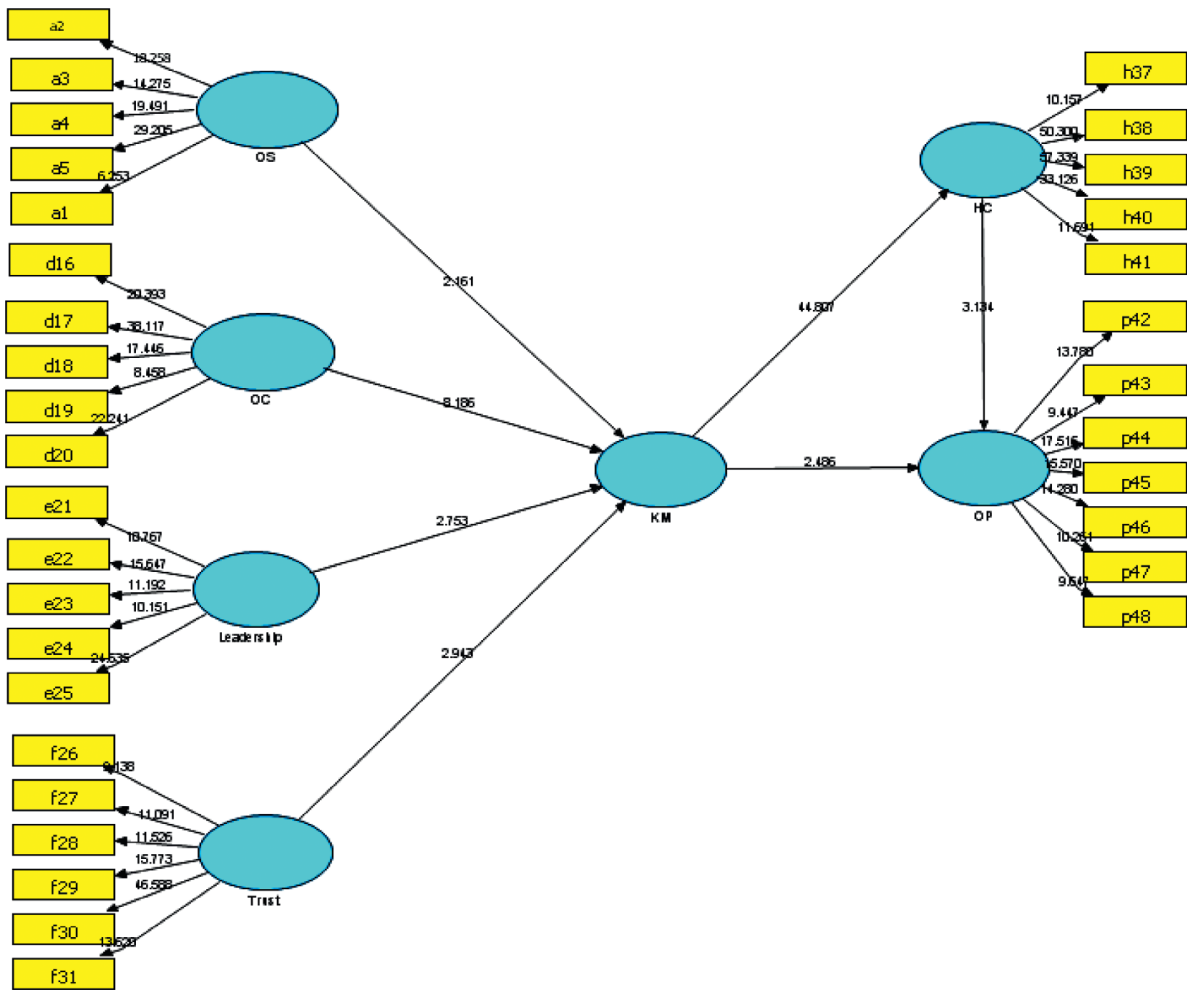

FIgURE 5: $t$-statistics of research model after eliminating insignificant paths.

TABLE 10: Summary and conclusion.

\begin{tabular}{|c|c|c|c|c|}
\hline Hypothesis & Relationship & Path coefficient & $t$-statistics & Result \\
\hline Hypothesis 1 & Organizational structure $\longrightarrow$ knowledge management & 0.182 & 2.161 & Confirmed \\
\hline Hypothesis 4 & Organizational culture $\longrightarrow$ knowledge management & 0.625 & 8.186 & Confirmed \\
\hline Hypothesis 5 & Organizational leadership $\longrightarrow$ knowledge management & 0.198 & 2.753 & Confirmed \\
\hline Hypothesis 6 & Trust in workplace $\longrightarrow$ knowledge management & 0.308 & 2.943 & Confirmed \\
\hline Hypothesis 7 & Knowledge management $\longrightarrow$ human capital development & 0.891 & 44.807 & Confirmed \\
\hline Hypothesis 8 & Human capital development $\longrightarrow$ performance & 0.487 & 3.134 & Confirmed \\
\hline Hypothesis 9 & Knowledge management $\longrightarrow$ organizational performance & 0.387 & 2.486 & Confirmed \\
\hline
\end{tabular}

performance, and also the mediating effect of human capital in the relationship between knowledge management and organizational performance. First, this study identifies the factors affecting the knowledge management processes and facilitating the implementation of an integrated knowledgebased system. Finally, this study shows that knowledge management, both directly and through the human capital variable, has an effective role in improving organizational performance. Designing and implementing this research model and evaluating it with PLS software help researchers to implement a sustainable knowledge management system in any organization to remain in today's competitive markets.

The findings of this study are in line with the results obtained by other research such as by Zheng et al. [43] and Islam et al. [22] which dealt with the positive impact of organizational structure on the knowledge management process as well as knowledge sharing and dissemination. Also, the hypothesis of the impact of strategy on knowledge management was rejected in this paper, which can be further analyzed in other cases and organizations. The hypothesis of the effect of technology on knowledge management was also rejected, which is consistent with the study conducted by Fernandes [62]. This study demonstrated the relationship between culture and knowledge management and the results are similar to the ones obtained by Afshari et al. [24] which showed that culture directly and indirectly affects knowledge management as well as the results obtained by Islam et al. [22] which demonstrated that culture has an impact on knowledge sharing in the organization.

However, Fernandes [62] could not show the relationship between culture and knowledge management and rejected the hypothesis. Finally, the hypotheses of the relationship between leadership and trust in knowledge management were accepted in this study, which is also consistent with the study conducted by Paliszkiewicz et al. [29]. Therefore, the findings of this paper augment the literature [19, 29]. 
Based on the findings of this study, the hypothesis of the impact of knowledge management on organizational performance was accepted. It should be noted that several studies have shown the impact of knowledge management and knowledge management processes on organizational performance $[19,29,53,55]$. This shows the importance of knowledge in improving the performance and promotion of the organization. Finally, the mediating role of human capital in the relationship between knowledge management and performance was also investigated and shown in this study which is also consistent with the results of research conducted by Cooper et al. [53].

\section{Conclusion}

Organizational behavior has a relevant role in the internal processes of knowledge management. The organizations must create the necessary conditions to encourage their employees to transfer their knowledge by contributing to the maturity of the knowledge management [63]. Given the positive effects of the four variables of organizational structure, culture, leadership, and trust on knowledge management, it can be concluded that traditional organizational plans do not meet the current needs, and fundamental changes must be made in organizational structures. Casual relationships play an important role in shaping the organizational structure. Casual relationships are the key aspects that distinguish machine and organic structures and are the determining dimensions of structure in knowledgebased organizations. The organizational structure must be sufficiently flexible and dynamic, so that communication is not limited to team, departmental, and even organizational boundaries, and it is easy for employees to communicate with the environment outside the organization. In other words, the informal aspect of organizational structure plays an important role in the development of interactions. As a result, organizations are advised to examine the capability of their different parts in order to delegate possible responsibilities to employees to increase the capacity of the employees on the one hand and to break the barriers of official bureaucracy and organizational hierarchies which hinder the development of talent and the fair and just distribution of information on the other hand.

There are six guidelines for knowledge managers and organizational leaders: (1) leaders can apply knowledge management tools and programs to promote a certain change in culture; however, this needs persistence and tenacity and using a wide range of methods and tools supported by a clear appropriate logic. (2) Supporting and promoting individuals with the appropriate attitudes and who are capable of becoming role models are recommended in order to encourage local influence. (3) Communication technology can ease culture adjustment, provided that it is accompanied by teaching and training to make sure that new behaviors are adopted by people in their everyday practices. (4) A knowledge management program can be offered according to the simple concepts of culture change. Eliminating obstacles to performance improvement is valued, but it does not change the long-term methods, norms, and assumptions, which form the organizational culture. (5) If organizational culture requires a change, a formal evaluation must be conducted to see which aspect needs change and why. (6) Short-term activities and advice are not recommended for changing deeply rooted assumptions and values [64]. One of the major barriers to knowledge management is that people do not want to share their knowledge for any reason and use it exclusively for their own personal development, because there may be a misconception that since knowledge is power, it should not be lost. Cultural factors in the organization, such as the creation of work teams and the sharing of work and trust among employees, will allow the flow of knowledge to spread freely throughout the organization and will also play an important role in the creation, acquisition, and dissemination of knowledge. Therefore, it is recommended that organizations give employees more freedom to act, individuals collaborate more in doing their work, and managers try to build a closer relationship between employees. It is also suggested that leaders should be guided by values and principles. They need to be aware of their strengths and weaknesses and constantly look for opportunities to learn. The leader is always in conflict with the status quo and is improving the environment in the organization. The leader focuses on all the individuals in the organization, building trust among team members, as well as establishing the necessary organizational cultures as organizational behaviors. Finally, the organization must foster a culture of trust in the workplace because trust is the foundation of a highly cooperative work environment that leads to knowledge sharing. Thus, in order to help employees to overcome their unwillingness to share their knowledge, the following must be fostered: trust in others, trust in the organization, and self-confidence [19]. By forming work teams based on similar goals within the organization and by team-based activities and programs, trust can be enhanced among individuals, because in the absence of trust, team members always play roles without genuine and sincere contribution, and it reduces their efficiency. Lack of trust also affects customer's morale and satisfaction.

According to the research results, human capital in the organization can be enhanced by knowledge management which includes knowledge creation, identification, sharing, and application [5]. More attention for adopting modern training is essential for identifying and eliminating the weaknesses along with enhancing employees' abilities, skills, and their cooperation as an effective way for solving problems [65]. To this end, it is suggested that human capital knowledge as a competitive advantage in the organization be enhanced by creating a culture of learning in the organization, sharing of information and knowledge among employees, job rotation, development and growth of the staff, recruitment and hiring of talented and capable individuals, promotion of staff competence, support of teamwork, etc. The benefits of applying knowledge management may include more productivity of human capital, presenting valueadded goods and services, enhancing customer satisfaction, reducing rework, avoiding mistakes, stimulating creativity and innovation, saving time, and creating closer relationship with customers, which all lead to improving the 
organizational performance. Based on the research results, it is recommended that organizations provide the necessary infrastructure to enhance their performance by boosting the effect of organizational structure, strategy, technology, culture, leadership, and trust on knowledge management.

This research was conducted at a specific time frame in Afghanistan, which may yield different results at other times as well as in other organizations or countries. Since other organizations or countries have different cultures and structures, it is recommended to examine this model in other countries and organizations preferably with larger sample sizes. In addition, it should be noted that six affecting factors including structure, culture, strategy, technology, leadership, and trust were investigated in the case study. Hence, as a suggestion for future studies, other influencing factors can be added to the model. The aforementioned six factors may also have relationship with each other, which has not been addressed in this study to avoid the complexity of the model. Therefore, examining the mutual relationships between these factors can be the topic of future studies. Finally, further research can scrutinize the impact of leadership and trust factors on knowledge management and organizational performance.

\section{Data Availability}

Data used to support the findings of this study are available on request.

\section{Conflicts of Interest}

The authors declare that they have no conflicts of interest.

\section{References}

[1] L. Taskin and G. Van Bunnen, "Knowledge management through the development of knowledge repositories: towards work degradation," New Technology, Work and Employment, vol. 30, no. 2, pp. 158-172, 2015.

[2] G. D. Bhatt, "Knowledge management in organizations: examining the interaction between technologies, techniques, and people," Journal of Knowledge Management, vol. 5, no. 1, pp. 68-75, 2001.

[3] B. Y. Obeidat, M. M. Al-Suradi, R. e. Masa'deh, and A. Tarhini, "The impact of knowledge management on innovation," Management Research Review, vol. 39, no. 10, pp. 1214-1238, 2016.

[4] P. K. Singh, "Knowledge strategy, sharing behavior and performance," Management Research Review, vol. 41, no. 3, pp. 395-411, 2018.

[5] A. Iqbal, F. Latif, F. Marimon, U. F. Sahibzada, and S. Hussain, "From knowledge management to organizational performance," Journal of Enterprise Information Management, vol. 32, no. 1, pp. 36-59, 2019.

[6] B. X. Hsu and Y. M. Chen, "Why university matters: the impact of university resources on foreign workers' human and social capital accumulation," International Entrepreneurship and Management Journal, vol. 17, pp. 1-17, 2020.

[7] S. Razzaq, M. Shujahat, S. Hussain et al., "Knowledge management, organizational commitment and knowledge-worker performance," Business Process Management Journal, vol. 25, no. 5, 2019.
[8] C. Archer-Brown and J. Kietzmann, "Strategic knowledge management and enterprise social media," Journal of Knowledge Management, vol. 22, no. 6, 2018.

[9] I. C. Hsu, "Knowledge sharing practices as a facilitating factor for improving organizational performance through human capital: a preliminary test," Expert Systems with Applications, vol. 35, no. 3, pp. 1316-1326, 2008.

[10] C. López-Nicolás and Á. L. Meroño-Cerdán, "Strategic knowledge management, innovation and performance," International Journal of Information Management, vol. 31, no. 6, pp. 502-509, 2011.

[11] Z. Wang, P. N. Sharma, and J. Cao, "From knowledge sharing to firm performance: a predictive model comparison," Journal of Business Research, vol. 69, no. 10, pp. 4650-4658, 2016.

[12] J. W. Huang and Y. H. Li, “The mediating effect of knowledge management on social interaction and innovation performance," International Journal of Manpower, vol. 30, no. 3, 2009.

[13] R. M. Grant, "Reflections on knowledge-based approaches to the organization of production," Journal of Management \& Governance, vol. 17, no. 3, pp. 541-558, 2013.

[14] S. M. Jasimuddin and Z. Zhang, "Transferring stored knowledge and storing transferred knowledge," Information Systems Management, vol. 28, no. 1, pp. 84-94, 2011.

[15] G. Santoro and A. Usai, "Knowledge exploration and ICT knowledge exploitation through human resource management," Management Research Review, vol. 41, no. 6, pp. 701-715, 2018.

[16] M. Du Plessis, "The role of knowledge management in innovation," Journal of Knowledge Management, vol. 11, no. 4, pp. 20-29, 2007.

[17] P. Oluikpe, "Developing a corporate knowledge management strategy," Journal of Knowledge Management, vol. 16, no. 6, pp. 862-878, 2012.

[18] S. Alaarj, Z. Abidin-Mohamed, and U. S. B. A. Bustamam, "Mediating role of trust on the effects of knowledge management capabilities on organizational performance," Procedia - Social and Behavioral Sciences, vol. 235, pp. 729-738, 2016.

[19] A. Koohang, J. Paliszkiewicz, and J. Goluchowski, "The impact of leadership on trust, knowledge management, and organizational performance," Industrial Management \& Data Systems, vol. 117, no. 3, pp. 521-537, 2017.

[20] Y. Cader, K. Kathleen O’Neill, A. A. Blooshi, A. A. Bakheet Al Shouq, B. Hussain Mohamed Fadaaq, and F. Galal Ali, "Knowledge management in Islamic and conventional banks in the United Arab Emirates," Management Research Review, vol. 36, no. 4, pp. 388-399, 2013.

[21] M. Mahmoudsalehi, R. Moradkhannejad, and K. Safari, "How knowledge management is affected by organizational structure," The Learning Organization, vol. 19, no. 6, pp. 518-528, 2012.

[22] M. Z. Islam, S. M. Jasimuddin, and I. Hasan, "Organizational culture, structure, technology infrastructure and knowledge sharing," Vine, vol. 45, no. 1, pp. 67-88, 2015.

[23] S. Jamshed and N. Majeed, "Relationship between team culture and team performance through lens of knowledge sharing and team emotional intelligence," Journal of Knowledge Management, vol. 23, no. 1, pp. 90-109, 2019.

[24] L. Afshari, A. H. Nasab, and G. Dickson, "Organizational culture, social capital, and knowledge management," International Journal of Knowledge Management, vol. 16, no. 2, pp. 52-66, 2020. 
[25] M. S. Nikabadi, S. Bagheri, and S. A. Mohammadi-Hoseini, "Effects of knowledge management strategy and organizational learning capability on innovation-driven performance in an oil company," Knowledge Management \& E-Learning: An International Journal, vol. 8, no. 2, pp. 334-355, 2016.

[26] R. Borges, "Tacit knowledge sharing between IT workers," Management Research Review, vol. 36, no. 1, 2012.

[27] A. Novak, K. Breznik, and S. Natek, "How leaders can initiate knowledge management in organizations: role of leadership style in building knowledge infrastructure," Human Systems Management, vol. 39, no. 1, pp. 37-50, 2020.

[28] J. Paliszkiewicz and A. Koohang, "Organizational trust as a foundation for knowledge sharing and its influence on organizational performance," Online Journal of Applied Knowledge Management, vol. 1, no. 2, pp. 116-127, 2013.

[29] J. Paliszkiewicz, J. Gołuchowski, and A. Koohang, "Leadership, trust, and knowledge management in relation to organizational performance: developing an instrument," Online Journal of Applied Knowledge Management, vol. 3, no. 2, pp. 19-35, 2015.

[30] T. H. Kuo, "How expected benefit and trust influence knowledge sharing," Industrial Management \& Data Systems, vol. 113, no. 4, pp. 506-522, 2013.

[31] M. S. Rahman, N. M. Daud, and M. Raman, "Knowledge sharing behaviour among non-academic staff in higher learning institutes: the role of trust and perceived risk'," Knowledge Management \& E-Learning: An International Journal, vol. 10, no. 1, pp. 113-124, 2018.

[32] K. A. Ghani, V. Jayabalan, and M. Sugumar, "Impact of advanced manufacturing technology on organizational structure," The Journal of High Technology Management Research, vol. 13, no. 2, pp. 157-175, 2002.

[33] C. J. Chen and J. W. Huang, "How organizational climate and structure affect knowledge management-the social interaction perspective," International Journal of Information Management, vol. 27, no. 2, pp. 104-118, 2007.

[34] G. Ragsdell, L. E. Z. Cantu, and C. E. Mondragon, "Knowledge management in Mexican NPOs: a comparative study in organizations with a local and national presence," Journal of Knowledge Management, vol. 20, no. 1, pp. 69-87, 2016.

[35] M. Alavi and D. E. Leidner, "Review: knowledge management and knowledge management systems: conceptual foundations and research issues," MIS Quarterly, vol. 25, no. 1, pp. 107-136, 2001.

[36] L.-R. Yang, J.-H. Chen, and H.-W. Wang, "Assessing impacts of information technology on project success through knowledge management practice," Automation in Construction, vol. 22, pp. 182-191, 2012.

[37] C. T. Ho, "The relationship between knowledge management enablers and performance," Industrial Management \& Data Systems, vol. 109, no. 1, pp. 98-117, 2009.

[38] L. Trong Tuan, "Behind knowledge transfer," Management Decision, vol. 50, no. 3, pp. 459-478, 2012.

[39] J. P. J. De Jong and D. N. Den Hartog, "How leaders influence employees' innovative behaviour," European Journal of Innovation Management, vol. 10, no. 1, pp. 41-64, 2007.

[40] G. R. Berry, "A cross-disciplinary literature review: examining trust on virtual teams," Performance Improvement Quarterly, vol. 24, no. 3, pp. 9-28, 2011.

[41] S. Park and E.-J. Kim, "Fostering organizational learning through leadership and knowledge sharing," Journal of Knowledge Management, vol. 22, no. 6, pp. 1408-1423, 2018.
[42] C. Curado and S. Vieira, "Trust, knowledge sharing and organizational commitment in SMEs," Personnel Review, vol. 48, no. 6, 2019.

[43] W. Zheng, B. Yang, and G. N. McLean, "Linking organizational culture, structure, strategy, and organizational effectiveness: mediating role of knowledge management," Journal of Business Research, vol. 63, no. 7, pp. 763-771, 2010.

[44] Y. Karlinsky-Shichor and M. Zviran, "Factors influencing perceived benefits and user satisfaction in knowledge management systems," Information Systems Management, vol. 33, no. 1, pp. 55-73, 2016.

[45] R. e. Masa'deh, R. Shannak, M. Maqableh, and A. Tarhini, "The impact of knowledge management on job performance in higher education: the case of the University of Jordan," Journal of Enterprise Information Management, vol. 30, no. 2, pp. 244-262, 2017.

[46] S.-M. Tseng, "The effect of knowledge management capability and customer knowledge gaps on corporate performance," Journal of Enterprise Information Management, vol. 29, no. 1, pp. 51-71, 2016.

[47] S.-M. Tseng, "Knowledge management capability, customer relationship management, and service quality," Journal of Enterprise Information Management, vol. 29, no. 2, pp. 202221, 2016.

[48] G. Assaker, R. Hallak, and P. O'Connor, "Examining heterogeneity through response-based unit segmentation in PLSSEM: a study of human capital and firm performance in upscale restaurants," Current Issues in Tourism, vol. 23, no. 2, pp. 137-152, 2020.

[49] C. P. B. Hardeep, "Examining intellectual capital and competitive advantage relationship," International Journal of Bank Marketing, vol. 33, no. 3, pp. 376-399, 2015.

[50] L. W. Mihardjo, K. Jermsittiparsert, U. Ahmed, T. Chankoson, and H. I. Hussain, "Impact of key HR practices (human capital, training and rewards) on service recovery performance with mediating role of employee commitment of the Takaful industry of the Southeast Asian region," Education + Training, vol. 63, no. 1, 2020.

[51] S. K. Singh, S. Mittal, A. Sengupta, and R. K. Pradhan, "A dual-pathway model of knowledge exchange: linking human and psychosocial capital with prosocial knowledge effectiveness," Journal of Knowledge Management, vol. 23, no. 5, 2019.

[52] M. Piri, M. Jasemi, and M. Abdi, "Intellectual capital and knowledge management in the Iranian space industries," VINE, vol. 43, no. 3, pp. 341-356, 2013.

[53] A. L. Cooper, J. R. Huscroft, R. E. Overstreet, and B. T. Hazen, "Knowledge management for logistics service providers: the role of learning culture," Industrial Management \& Data Systems, vol. 116, no. 3, pp. 584-602, 2016.

[54] M. Tubigi and S. Alshawi, "The impact of knowledge management processes on organisational performance," Journal of Enterprise Information Management, vol. 28, no. 2, pp. 167185, 2015.

[55] C. Valmohammadi and M. Ahmadi, "The impact of knowledge management practices on organizational performance," Journal of Enterprise Information Management, vol. 28, no. 1, pp. 131-159, 2015.

[56] O. A. Ogunmokun, K. K. Eluwole, T. Avci, T. T. Lasisi, and J. E. Ikhide, "Propensity to trust and knowledge sharing behavior: an evaluation of importance-performance analysis among Nigerian restaurant employees," Tourism Management Perspectives, vol. 33, p. 100590, 2020. 
[57] U. F. Sahibzada, C. Jianfeng, K. F. Latif, Z. Shafait, and H. F. Sahibzada, "Interpreting the impact of knowledge management processes on organizational performance in Chinese higher education: mediating role of knowledge worker productivity," Studies in Higher Education, pp. 1-18, 2020.

[58] U. F. Sahibzada, C. Jianfeng, K. F. Latif, S. A. Shah, and H. F. Sahibzada, "Refuelling knowledge management processes towards organisational performance: mediating role of creative organisational learning," Knowledge Management Research \& Practice, pp. 1-13, 2020.

[59] S. Samad, "Achieving innovative firm performance through human capital and the effect of social capital," Management \& Marketing. Challenges for the Knowledge Society, vol. 15, no. 2, pp. 326-344, 2020.

[60] M. K. Imran, M. Ilyas, and U. Aslam, "Organizational learning through transformational leadership," The Learning Organization, vol. 23, no. 4, pp. 232-248, 2016.

[61] J.-G. Park and J. Lee, "Knowledge sharing in information systems development projects: explicating the role of dependence and trust," International Journal of Project Management, vol. 32, no. 1, pp. 153-165, 2014.

[62] A. A. R. Fernandes, "The effect of organization culture and technology on motivation, knowledge asset and knowledge management," International Journal of Law and Management, vol. 60 , no. $5,2018$.

[63] J. M. R. Marques, J. L. La Falce, F. M. F. R. Marques, C. F. De Muylder, and J. T. M. Silva, "The relationship between organizational commitment, knowledge transfer and knowledge management maturity," Journal of Knowledge Management, vol. 23, no. 3, pp. 489-507, 2019.

[64] A. Corfield and R. Paton, "Investigating knowledge management: can KM really change organisational culture?" Journal of Knowledge Management, vol. 20, no. 1, pp. 88-103, 2016.

[65] N. A. W. Al-Qatawneh, S. J. Al-Tarawneh, N. A. W. AlQatawneh, and R. M. Al-Adaileh, "The impact of knowledge management processes on operational performance as mediated by IT agility," International Review of Management and Marketing, vol. 9, no. 1, pp. 36-43, 2019. 